\title{
Optimizing patient-centeredness in the transitions of healthcare systems in low- and middle-income countries
}

\author{
Yodi Mahendradhata ${ }^{1,2^{*}}$, Aurélia Souares ${ }^{2}$, Revati Phalkey ${ }^{2}$ and Rainer Sauerborn ${ }^{2}$
}

\begin{abstract}
Background: Patient-centeredness is necessary for quality of care. Wide-spread incorporation of patient-centered practices across the health system is challenging in low and middle income countries (LMICS) given the complexity of scarce resources, competing priorities and rapidly changing social, economic and political landscapes. Health service managers and policy makers in these settings would benefit from a framework that allows comprehension and anticipation of forthcoming challenges for optimizing patient-centeredness in healthcare delivery. We set out to formulate such a framework, based primarily on analysis of general patterns of healthcare system evolution in LMICs and the current literature.

Discussion: We suggest that optimization of patient-centeredness in LMICs can be thought of as occurring in four phases, in accordance to particular patterns of macro transitions. Phase I is characterized by a deeply fragmented system based on conventional clinical approaches, dealing primarily with simple acute conditions. In phase II, the healthcare systems deal with increasing chronic cases and require redesign of existing acute-oriented services. In phase III, health services are increasingly confronted with multimorbid patients, requiring more coordinated and integrated care. Complex health care needs in individual patients are increasingly the norm in Phase IV, requiring the most optimal form of patient-centered care. This framework helps to identify and map the key challenges and implications for research, policy and practice, associated with the transitions ahead of time.
\end{abstract}

Summary: We have developed a framework based on observed patterns of healthcare and related macro-transitions in LMICs. The framework provides insights into critical issues to be considered by health service managers and policy makers.

Keywords: Patient centered care, Health services, Global health

\section{Background}

Patient-centered care is a universal necessity. The Institute of Medicine (IoM) - the health arm of the United States National Academy of Sciences - considers it one of the key elements of high quality care and describes it as "providing care that is respectful of and responsive to individual patient preferences, needs, and values, and ensures that patient values guide all clinical decisions [1]". IoM has further elaborated the dimensions of patientcentered care as: (1) respect for patients' values,

\footnotetext{
* Correspondence: yodi_mahendradhata@yahoo.co.uk

${ }^{1}$ Center for Health Policy and Management, Faculty of Medicine, Gadjah Mada University, Sekip Utara, Yogyakarta 55281, Indonesia

${ }^{2}$ Institute of Public Health, Faculty of Medicine, University of Heidelberg, Heidelberg, Germany
}

preferences and needs; (2) coordination and integration of care; (3) information, communication, and education; (4) physical comfort; (5) emotional support; and (6) involvement of family and friends. Patient centeredness has been shown to lead to better patient satisfaction; outcomes; quality of life and improved care utilization [2-5].

The care that patients in low- and middle-income countries (LMICs) have been receiving has undoubtedly been vastly improved, however, much is left to be achieved [6-8]. Consider the following case study, which illustrates the lack of patient-centered care in a middle income country: "Mr $\mathrm{X}$ is a 60 years old patient diagnosed with Diabetes Mellitus (DM) and hypertension eight years ago. His internist prescribed him a regimen consisting of seven drugs, which he has adhered to 
diligently, as well as coming in for monthly check-ups at a hospital. Two-months ago he started to suffer from persistent cough. He went to a pulmonologist at another hospital, who diagnosed him with Tuberculosis (TB) and additionally prescribed a treatment regimen consisting of five drugs. During the course of treatment he experienced nausea, vomiting and skin rash. He seriously considered discontinuing the drugs. He then consulted both doctors separately, who apparently had conflicting opinions and had not communicated with each other. Thus, he is left to make his own decision on the continuation of his treatment, based on conflicting advices".

Uncoordinated care, as illustrated above, is one of the major issues that limits effective patient management [9]. Other major issues include: poor communication and provision of information; poor organisation of service delivery and long waiting times; insufficient facilitation of self care; and lack of patient and carer involvement in decision making. Patients are dissatisfied with the quality of the interaction with their provider, as many providers focus on the disease alone rather than on the patient [10].

Similar cases are also found in high-income countries, however, the challenges are evidently much greater in LMICs as policymakers struggle with scarce resources, competing priorities and rapidly changing environments. These challenges notwithstanding, patient-centeredness is feasible even in LMICs [11]. The challenge is how to realize it sustainably and on a large scale, given the complex environment. Thus, we set out to formulate a framework for policymakers and health service managers to aid in their comprehension and anticipation of challenges, for optimizing patient-centered care in these countries. We base it on an in depth analysis of general patterns of healthcare systems in LMICs and current literature.

\section{A framework of healthcare system transitions in LMICs}

Societies have a life cycle [12]. Omran depicted how disease patterns evolve over time in societies, in response to, among other factors, demographic transition and economic development, resulting in an epidemiological transition [13]. Accordingly, infectious diseases and nutritional deficiencies are predominate in a society in which the majority of the population is young. Although chronic noncommunicable diseases (NCDs) become more prevalent as the population becomes more mature, infectious diseases still prevail. NCDs predominate in an aging population. Rayner and Lang [14] more recently proposed a longer list of macro-transitions to establish a framework for ecological public health. Some of these transitions are relatively familiar to the global health community (e.g. urban, nutrition, biological), others are less familiar (e.g. cultural, democratic, energy). They assert that all of those transitions shape health and that none of the transitions should be viewed in isolation as it is their totality that is significant. This inevitably leads to complexity, but need not paralyse public health thinking and action [14].

The complex patterns of macro-transitions arguably have consequences for healthcare systems, including their extent of patient-centeredness. Notably, high-income countries experienced population ageing after they became wealthy; most LMICs, however, will have to cope with such transitions prior to becoming wealthy. This brings us to the critical question of how can LMICs be offered a lead time in facing the inevitable transitions. A pragmatic way forward is, thus, to conceptualize how healthcare systems should be systematically transformed in response to these multiple transitions in LMICs.

We suggest that healthcare systems in LMICs can transform over time, towards an optimal form of patientcenteredness, both as a result and as a response to large scale transitions. Such transformation can be thought of as occurring in four generally sequential phases along a continuum: from a deeply fragmented system dealing primarily with simple conditions based on conventional clinical approaches to an integrated system equipped to deal with complex conditions based on interdisciplinary approaches. These phases are both driven by and are in response to macro transitions that evolve simultaneously. The patterns of interactions between the phases and the transitions would vary, but certain typical patterns should be identifiable and investigated through further studies. We present an illustration of a potential pattern (Figure 1). The phases are elaborated below. Table 1 presents a summary of the phases while Table 2 presents illustrative action points.

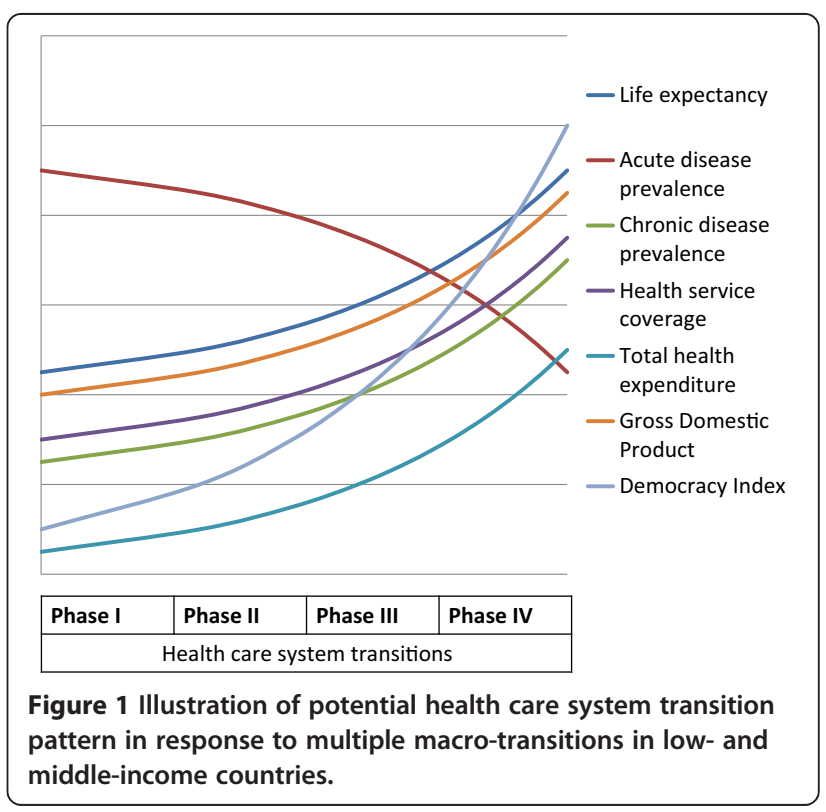


Table 1 Phases of healthcare system transitions in low- and middle-income countries

\begin{tabular}{llll}
\hline & Typical patient profile & Example of a typical case & Typical healthcare system feature \\
\hline Phase I & $\begin{array}{l}\text { Patients with } \\
\text { acute conditions }\end{array}$ & Children with malaria & Acute care \\
Phase II & Patients with chronic condition & Elderly patients with lung cancer & Chronic care in parallel with acute care \\
Phase III & Patients with comorbidities & Patients with Tuberculosis and Diabetes & Integrated care \\
Phase IV & Complex patients & $\begin{array}{l}\text { Single-parent with two children, Diabetes, obese, smoking, } \\
\text { alcoholic, recently unemployed }\end{array}$ & Individualized/customized care \\
\hline
\end{tabular}

\section{Phase I}

In this initial stage, there is very limited recognition of the need for patient-centered care. The typical patients are young with acute (mainly communicable) conditions. This phase is characterised by a fragmented health system, dominated by multiple vertical programmes. These programmes are centrally administered, heavily controlled and focus on a few specific conditions (commonly linked to current donors' priorities, e.g. Malaria) to maximize likelihood of impact [15]. Healthcare services in these settings are designed to manage episodic visits of acute conditions. Healthcare workers are limited, scarce at the periphery, and trained primarily to diagnose and treat acute conditions. They routinely diagnose and treat as many patients as possible within the limited resources, thus optimizing their capacities, even in routine care.

Many of these countries are entering the epidemiologic transition and would benefit from early preparedness, through studies documenting disease trends and studies on optimizing care for chronic communicable diseases, e.g. HIV/AIDS. They also need evidence for shifting to a more horizontal system, integrating specific disease control interventions into general healthcare services. In this context, they would benefit from development of integrated clinical diagnosis and treatment algorithm, Strengthening general healthcare system should be a priority for policy makers in this phase. In the meanwhile, health service managers should ensure that care is provided in a manner that is respectful to patients and their families.

\section{Phase II}

The second phase starts with the recognition of an increase in patients with non- communicable diseases. The socio-economic conditions are gradually improving and life expectancy rises. Treatment adherence becomes increasingly important as more patients need drugs for a longer period. Patients are more knowledgeable of their diseases and demand better care. There is growing awareness of the inadequacy of health services (originally designed to manage acute conditions), leading to efforts to adapt best practices of chronic care from developed countries and from locally existing chronic communicable disease services, e.g. Tuberculosis (TB) [16].

These countries are experiencing a dual burden of communicable and non-communicable diseases [17]. There are shared features across these disease categories, such as common risk populations and the need for

Table 2 Illustrative action points for key stakeholders in different phases of healthcare system transitions

\begin{tabular}{|c|c|c|c|c|}
\hline & Phase I & Phase II & Phase III & Phase IV \\
\hline $\begin{array}{l}\text { Health } \\
\text { service } \\
\text { manager }\end{array}$ & $\begin{array}{l}\text { Promote healthcare that is } \\
\text { respectful of patients and } \\
\text { families }\end{array}$ & $\begin{array}{l}\text { Redesign services to meet } \\
\text { requirements of acute and } \\
\text { chronic conditions }\end{array}$ & $\begin{array}{l}\text { Strengthen coordination of care; } \\
\text { promote interdisciplinary } \\
\text { teamwork for managing } \\
\text { multi-morbidities }\end{array}$ & $\begin{array}{l}\text { Promote institutional policies that } \\
\text { minimize disruptions of effective } \\
\text { communications and foster } \\
\text { customized/ individualized care }\end{array}$ \\
\hline Policy maker & $\begin{array}{l}\text { Formulate policies to } \\
\text { systematically integrate } \\
\text { vertical programs into } \\
\text { general healthcare services }\end{array}$ & $\begin{array}{l}\text { Establishing task forces/ } \\
\text { working groups at national } \\
\text { level to align interventions } \\
\text { for acute and chronic } \\
\text { conditions simultaneously }\end{array}$ & $\begin{array}{l}\text { Establish policies and programs } \\
\text { to support generalists and } \\
\text { inter-professional education } \\
\text { for managing multi-morbidities }\end{array}$ & $\begin{array}{l}\text { Setting targets that will allow } \\
\text { healthcare leaders to measure } \\
\text { progress toward } \\
\text { customized/individualized care }\end{array}$ \\
\hline Donor & $\begin{array}{l}\text { Provide more funding on } \\
\text { and technical assistance } \\
\text { for strengthening } \\
\text { general healthcare services }\end{array}$ & $\begin{array}{l}\text { Provide funding and technical } \\
\text { assistance for designing } \\
\text { strategies and services to } \\
\text { address acute and chronic } \\
\text { conditions simultaneously }\end{array}$ & $\begin{array}{l}\text { Provide technical assistance } \\
\text { for strengthening integrated } \\
\text { primary care for multi-morbidities }\end{array}$ & $\begin{array}{l}\text { Provide platform for sharing } \\
\text { best practices in } \\
\text { customized/individualized care }\end{array}$ \\
\hline $\begin{array}{l}\text { Scientific } \\
\text { community }\end{array}$ & $\begin{array}{l}\text { Provide evidence for shifting } \\
\text { toward more horizontal health } \\
\text { system; Develop integrated } \\
\text { clinical diagnosis and } \\
\text { treatment algorithm }\end{array}$ & $\begin{array}{l}\text { Investigate potential } \\
\text { synergies in policies, } \\
\text { programs and services for } \\
\text { addressing acute and chronic } \\
\text { conditions }\end{array}$ & $\begin{array}{l}\text { Studies to develop guidelines } \\
\text { for care of patients with multiple } \\
\text { conditions; models of coordinated } \\
\text { care; shared decision-making and } \\
\text { strategies to deal with } \\
\text { conflicting priorities }\end{array}$ & $\begin{array}{l}\text { Studies to support continuous } \\
\text { enhancement of efficient flexible } \\
\text { care management system that can } \\
\text { respond to patients' needs for } \\
\text { different levels of support }\end{array}$ \\
\hline
\end{tabular}


treatment adherence. Thus, there is arguably an opportunity to harness a combined approach. Unfortunately, the experts, institutions and policies that support management of communicable and non-communicable diseases in these settings, commonly remain as separate entities with limited interaction and alignment. There is an imminent risk of competing for funds to control either problem, rather than a fight against the double disease burden [12]. Hence, in order to move forward beyond this phase, there is a critical need to systematically document co-morbidities, particularly of communicable and non-communicable diseases, and identify and target potential synergies in case management. This needs to be complemented at the policy level by establishment of task forces/working groups aligning interventions to address both disease categories, capitalizing on existing capabilities, without competing for resources [16]. In the meanwhile, health service managers need to ensure that care is capable of effectively meeting the needs of acute and chronic conditions simultaneously.

\section{Phase III}

In this phase, there is rising awareness that many patients are presenting with more than one disease condition. The HIV epidemic demonstrated that the risk for developing TB can increase over four fold where both diseases are prevalent [12]. There is an increase in the simultaneous incidence of communicable and non communicable diseases in many patients. The interaction of diabetes with TB was first recognized several years ago, but subsequently forgotten by clinicians and public health experts, until diabetes rose exponentially in TBprevalent LMICs [12].

People with multimorbidity, in general, have a worse quality of life $[18,19]$. Expenditure on health care rises almost exponentially with the number of disorders that an individual has, and therefore, increasing multimorbidity generates financial pressure. The economic burden heightens the need to manage people with several illnesses in an efficient way. Furthermore, healthcare providers in LMICs generally see patients during brief visits. When patients have multiple conditions, screening, counseling, and treatment needs exceed the time available [20]. Thus, the healthcare providers are unable to meet these multiple demands, further complicated by inadequate system support and little guidance about how to manage multimorbid patients. These countries are eventually faced with a fundamental challenge to the single-disease focus that pervades conventional medical care.

Fundamentally, people with multimorbidity need more coordinated and diverse care [21]. Use of poorly coordinated services to manage individual diseases is inefficient, burdensome and unsafe [18]. Policy makers and health service managers, thus, need to ensure that approaches focusing on single diseases are complemented by support for generalists (mainly in primary care) providing continuity and coordination for people with multimorbidities. There is, therefore, a need for studies about strengthening integrated primary care, including studies that contribute toward: guidelines for caring for patients with multiple conditions; models of coordinated care; shared decision-making and strategies to deal effectively with conflicting priorities [22].

Socioeconomic, behavioral and environmental circumstances can also affect health outcomes and contribute to complexity [23]. Care plans need to be adjusted to address these issues, as they can become barriers to reaching congruence between patient and provider, leading to low treatment compliance and diminishing the physician's effectiveness in optimizing patient's health. Hence, there is a need to inform the care of complex patients, through interdisciplinary research, to lay the foundation for indepth understanding of the multiple sources of patient complexity (e.g. biological, socioeconomic, behavioral, environmental) and to better understand how care provision should be harmonized to optimize patients' health. Thus, health service researchers need to work with physicians, social scientists, complexity theorists, network experts, education experts, behavior analysts and scientists from other relevant disciplines to carry out much needed interdisciplinary studies on patient complexity in healthcare.

\section{Phase IV}

In the final phase, complex patients are increasingly the norm, rather than the exception. The features of the conditions range from complex to chaotic (unstructured randomness) [24]. There is a broad consensus among stakeholders, in this phase, that the purely biomedical model is inadequate and that patient management needs to be grounded in an alternative model, in which illnesses result from complex interactions between different system components [25].

In this phase, policy makers commit themselves to a coherent and coordinated effort to advance patient-centered care, setting targets that will allow healthcare leaders to measure progress toward patient-centeredness [26]. There is a clear and focused national policy to promote patientcentered care. Such policy drives healthcare organizations to move towards a culture of patient-centeredness by supporting patients in shared decision making and self- management. Such policies also encourage healthcare workers to acquire and maintain interpersonal competencies through intensive continuous education. Health service managers promote a culture of patientcenteredness through policies that minimize disruptions in effective communications and foster therapeutic relationships. 
As the population of complex patients grows, there is an increased demand for more intensive care management that may drain already limited resources [27]. Thus, research in this phase is needed to continuously tweak the system to more efficiently deliver optimum patientcentered care, including developing efficient flexible care management systems that can respond to patients' needs for different levels of support in a timely manner [27], i.e. customized/individualized care.

\section{Discussion}

We have presented a framework of healthcare system transitions in LMICs toward an optimum level of patientcenteredness. We are not the first in suggesting that macro transitions define the terrain within which health systems operate [12-14]. Our focus, however, represents a step forward in conceptualizing how LMICs could anticipate, prepare, and respond pragmatically to dynamic large scale transitions.

Needfully, the framework is a simplification of the complex reality: some phases may not be sequential as healthcare systems are constantly evolving and complex. Our framework is not meant to be prescriptive or predictive. These systems are non-predictable, but potentially comprehensible by observation and pattern recognition. The framework describes these observed patterns, examining the process of overall change and attempts to break it into manageable parts for policymakers in LMICs. It seems to provide insights into pragmatic steps which could be taken prior to subsequent macro-transition waves.

From a theoretical construction perspective, this framework is an initial proposition. It would evidently still need to undergo subsequent empirical testing, refinement, affirmation and extension. In the meanwhile, however, we believe that sharing the current proposition can promote deeper understanding of healthcare system transitions and optimization of patient-centeredness by stimulating investigative studies and discussions.

Dialogues on healthcare system transitions and optimization of patient-centeredness are now timely, as many LMICs are gearing up for universal coverage, with increasing focus on requirements for effective coverage [28]. Patient-centeredness is clearly required for effective care [29]. A unique window of opportunity is currently available to progress toward patient-centered care in LMICs. We recommend that the systematic transition for optimizing patient-centeredness now becomes a focal element for universal coverage policy in LMICs.

\section{Summary}

Patient-centeredness is a necessity for quality care, including care in low- and middle-income countries (LMICs). We present a conceptual framework for health service managers and policymakers in LMICs to better comprehend the challenges for optimizing patientcenteredness, through ongoing multiple macrotransitions. The framework describes observed general patterns, examines the processes of overall change and breaks it into smaller more comprehensible and, hence, manageable parts. These parts have been laid out in a continuum with four distinct phases, starting from a deeply fragmented system dealing primarily with simple conditions based on conventional medical approaches, to a highly integrated system equipped to deliver customized care for patients with complex conditions. The framework is not meant to be prescriptive nor predictive, rather it is meant to promote a deeper understanding of healthcare system transitions for optimizing patient-centeredness, by stimulating further investigations and discussions. Such discussions are timely as health systems in LMICs are currently gearing up for universal coverage, with increasing emphasis on requirements for effective coverage.

\section{Competing interests}

The authors declare that they have no competing interests.

\section{Authors' contributions}

YM is the first author, drafted the first and the revised version of the manuscript. RS is the mentoring author and gave major input to the philosophy behind the article, the key figure and to the set-up. RP contributed by revising the draft and making substantial additions to the text as well as editing of the manuscript and corrected the English. AS contributed to the conception and set-up of the manuscript and drew attention to key concepts for the discussion. All authors reviewed and approved the revised manuscript.

\section{Acknowledgements}

The work was supported by the Alexander von Humboldt Foundation through the Humboldt Research Fellowship for Experienced Researchers. The funder had no role in conception, decision to publish, or preparation of the manuscript. We thank Amy Rue Schiener for carefully reviewing the manuscript.

Received: 24 December 2013 Accepted: 8 September 2014 Published: 12 September 2014

\section{References}

1. Institute of Medicine: Crossing the Quality Chasm: A new Health System for the 21st Century. Washington DC: National Academies Press; 2001.

2. Little P, Everitt H, Williamson I, Warner G, Moore M, Gould C, Ferrier K: Paynes: Observational study of effect of patient centredness and positive approach on outcomes of general practice consultations. BMJ 2011, 323:908-911.

3. Mauksch L, Dugdale D, Dodson S, Epstein R: Relationship, communication, and efficiency in the medical encounter: creating a clinical model from a literature review. Arch Intern Med 2008, 13:1387-1395.

4. Stewart M, Brown J, Boon H, Galajda J, Meredith L, Sangster M: Evidence on patient- doctor communication. Cancer Prev Control 1999, 1:25-30.

5. Williams S, Weinman J, Dale J: Doctor-patient communication and patient satisfaction: a review. Fam Pract 1998, 5:480-492.

6. Berendes S, Heywood P, Oliver S, Garner P: Quality of private and public ambulatory health care in Low and middle income countries: systematic review of comparative studies. PLoS Med 2011, 4:e1000433.

7. Hoque D, Rahman M, Billah S, Savic M, Karim AQMR, Chowdhury EK, Hossain A, Musa SAJM, Kumar H, Malhotra S, Matin Z, Raina N, Weber MW, El Arifeen S: An assessment of the quality of care for children in eighteen randomly selected district and subdistrict hospitals in Bangladesh. BMC Pediatr 2012, 12:197.

8. Ruelas E, Gomez-Dante O, Leatherman S, Fortune T, Gay-Molina JG: Strengthening the quality agenda in health care in low- and middle- 
income countries: questions to consider. Int I Qual Health Care 2012, 6:553-557.

9. Mirzaei M, Aspin C, Essue B, Jeon YH, Dugdale P, Usherwood T, Leeder S: A patient- centred approach to health service delivery: improving health outcomes for people with chronic illness. BMC Health Serv Res 2013, 13:251.

10. Dwamena F, Holmes Rovner M, Gaulden CM, Jorgenson S, Sadigh G, Sikorskii A, Lewin S, Smith RC, Coffey J, Olomu A: Interventions for providers to promote a patient-centred approach in clinical consultations. Cochrane Database Syst Rev 2012, 12:CD003267. doi:10.1002/14651858. CD003267.pub2.

11. Njoroge A, Cassidy S, Williams V: Making patient-centred care a reality in the slums of eastern Nairobi. Int I Tuberc Lung Dis 2013, 10:S5-S8.

12. Bygbjerg IC: Double burden of noncommunicable and infectious diseases in developing countries. Science 2012, 6101:1499-1501.

13. Omran AR: The epidemiologic transition: a theory of the epidemiology of population change. Milbank Q 2005, 4:731-757. 1971.

14. Rayner G, Lang T: Ecological Public Health: Reshaping the Conditions for Good Health. New York: Routledge; 2012.

15. Stender S, Christensen A: Patient-centered primary health care: synergy potential for health systems strengthening. Int I Tuberc Lung Dis 2013, 10:S15-S21.

16. Marquez P, Farrington J: No more disease silos for sub-Saharan Africa. BMJ 2012, 345:e5812.

17. Remais J, Zeng G, Li G, Tian L, Engelgau M: Convergence of non-communicable and infectious diseases in low- and middle-income countries. Int J Epid 2012, 1:221-227.

18. Barnett K, Mercer S, Norbury M, Watt G, Wyke S, Guthrie B: Epidemiology of multimorbidity and implications for health care, research, and medical education: a cross-sectional study. Lancet 2012, 380:37-43.

19. Salisbury C: Multimorbidity: redesigning health care for people who use it. Lancet 2012, 380:7-9.

20. Piette J, Kerr E: The impact of comorbid chronic conditions on diabetes care. Diabetes Care 2006, 3:725-731.

21. Boyd C, Fortin M: Future of multimorbidity research: how should understanding of multimorbidity inform health system design. Public Health Rev 2010, 2:23.

22. Caughey G, Roughead E: Multimorbidity research challenges: where to go from here? J Comorbidity 2011, 1:8-10.

23. Safford M, Allison J, Kiefe C: Patient complexity: more than comorbidity. The vector model of complexity. J Gen Intern Med 2007, 3:382-390.

24. Kernick D: A theoretical framework for multimorbidity: from complicated to chaotic. Br J Gen Pract 2012. doi:10.3399/bjgp12X654740.

25. Nardi R, Scanelli G, Corrao S, Iori I, Mathieu G, Amatrian R: Co-morbidity does not reflect complexity in internal medicine patients. Eur J Intern Med 2007, 18:359-368.

26. Epstein R, Fiscella K, Lesser C, Stange K: Why the nation needs a policy push on patient-centered health care. Health Aff 2010, 8:1489-1495.

27. Bayliss E, Edwards A, Steiner J, Main D: Processes of care desired by elderly patients with multimorbidities. Fam Pract 2008, 25:287-293.

28. Campbell J: The route to effective coverage is through the health worker: there are no shortcuts. Lancet 2013, 9868:725.

29. Campbell SM, Roland MO, Buetow SA: Defining quality of care. Soc Sci Med 2000, 11:1611-1625

\section{Submit your next manuscript to BioMed Central and take full advantage of:}

- Convenient online submission

- Thorough peer review

- No space constraints or color figure charges

- Immediate publication on acceptance

- Inclusion in PubMed, CAS, Scopus and Google Scholar

- Research which is freely available for redistribution 